\title{
Atypical mycobacteriosis in a poorly compliant patient
}

\author{
Ana Isabel Pedroso, ${ }^{1,2}$ Inês Nabais, ${ }^{1}$ Inês Mourato Nunes, ${ }^{3}$ Gustavo Carvalho ${ }^{1}$
}

'Department of Internal Medicine, Hospital de Cascais Dr. José de Almeida, Alcabideche, Cascais, Portugal ${ }^{2}$ Department of Internal Medicine, Centro Hospitalar de Lisboa Ocidental EPE, Lisboa, Portugal

${ }^{3}$ Department of Internal Medicine, Hospital de Egas Moniz, Lisboa, Portugal

Correspondence to Dr Ana Isabel Pedroso, anaidap@gmail.com

Accepted 2 September 2017

\section{DESCRIPTION}

Non-tuberculous mycobacteriosis most frequently presents as chronic lung disease. ${ }^{1}$ Delayed diagnosis or even misdiagnosis occurs due to a great similarity in its clinical presentation to tuberculosis. ${ }^{2}$ Treatment often seems unprofitable since it is complex and prolonged, poorly tolerated and frequently ineffective in the elimination of the disease. ${ }^{3}$

The authors present a 68-year-old woman with a history of pulmonary tuberculosis 1 year before, for which she only completed 6 weeks of treatment

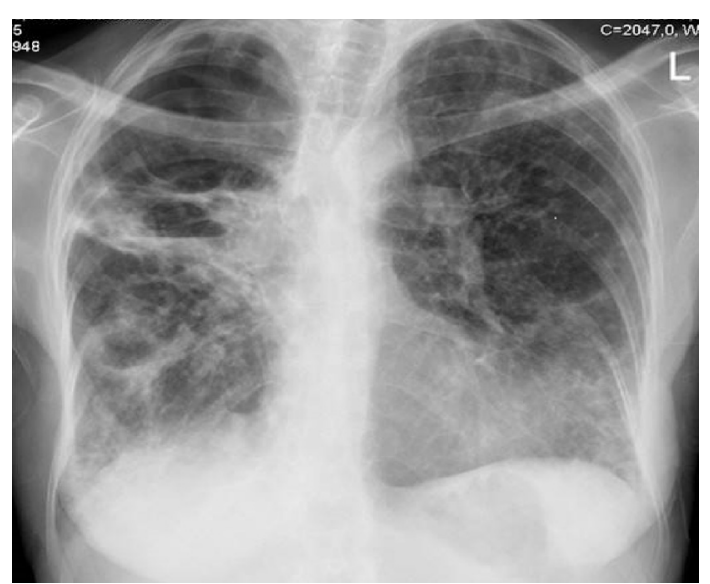

Figure 1 Chest X-ray. Two cavities in the right lung and a consolidation in the left lower lobe.

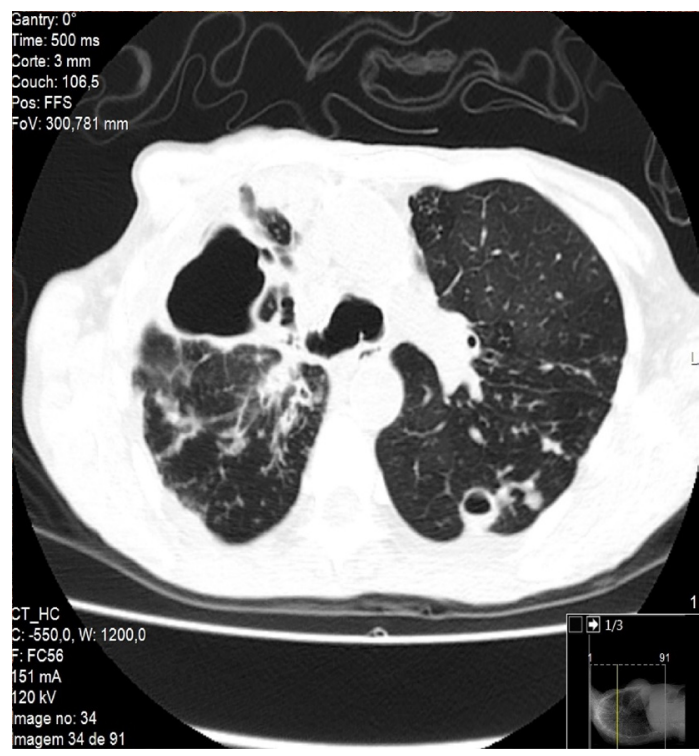

Figure 2 CT scan. Transversal plan-right upper lobe pneumatocele with multiple dispersed thick-walled lung cavitations. as well as follow-up, having abandoned both as she believed they went against her culture and religion. She was admitted with productive cough, weakness and weight loss. Blood tests revealed anaemia, thrombocytosis, elevated inflammatory markers, severe hypoalbuminaemia and negative HIV serology. The chest X-ray (figure 1) showed two cavities in the right lung and a consolidation in the left lower lobe. The chest CT scan (figures 2 and 3) showed right upper lobe pneumatocele with multiple dispersed thick-walled lung cavitations and multiple diffuse confluent nodules, diffuse reticulonodular interstitial infiltrates, multifocal bronchiectasis and several mediastinal lymph nodes, some with central necrosis. Tuberculosis reactivation was suspected. Although sputum acid-fast stain was negative, quantitative culture of bronchoalveolar lavage fluid was positive for Mycobacterium intracellulare. Treatment was started with azithromycin, rifampicin, ethambutol and amikacin, with progressive clinical improvement.

These striking images are the result of a rare infectious disease in an immunocompetent patient. Incomplete adherence to treatment has been identified as an extremely important factor in the control of mycobacterial infections as well as a major obstacle in the eradication of the disease. ${ }^{2}$

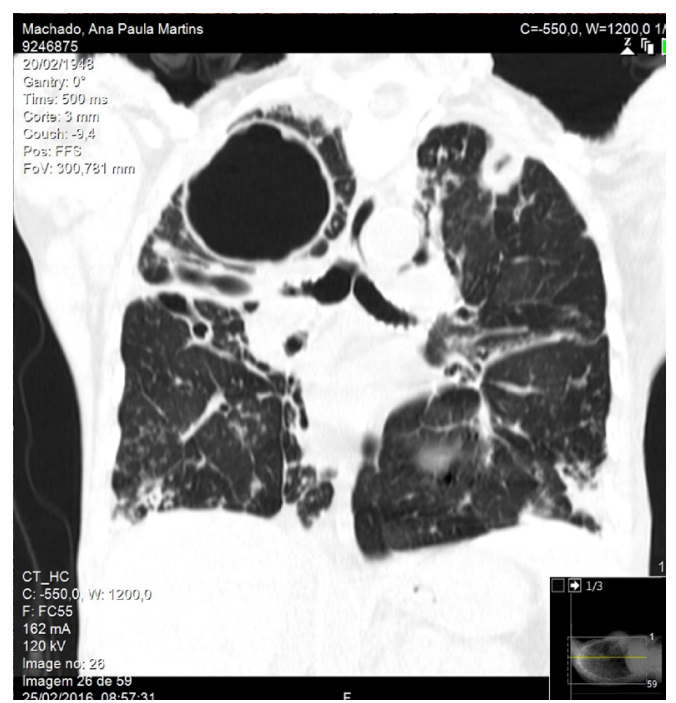

Figure 3 CT scan. Coronal plan—right upper lobe pneumatocele with multiple dispersed thick-walled lung cavitations and multiple diffuse confluent nodules, diffuse reticulonodular interstitial infiltrates, multifocal bronchiectasis and several mediastinal lymph nodes, some with central necrosis. 


\section{Learning points}

- Non-tuberculous mycobacteriosis is an infectious disease that has a complex and prolonged treatment, which contributes to poor therapeutic compliance.

- Imaging is fundamental for diagnosis: the American Thoracic Society and Infectious Disease Society of America's diagnostic criteria for non-tuberculous mycobacterial pulmonary infections include both: (1) imaging studies consistent with pulmonary disease and (2) recurrent isolation of mycobacteria from sputum or isolated from at least one bronchial wash in a symptomatic patient.

Contributors AIP: planning, conduct, reporting. IN: acquisition of data or analysis. $\mathrm{GC}$ and IMN: conception and design.
Competing interests None declared.

\section{Patient consent Obtained.}

Provenance and peer review Not commissioned; externally peer reviewed.

(C) BMJ Publishing Group Ltd (unless otherwise stated in the text of the article) 2018. All rights reserved. No commercial use is permitted unless otherwise expressly granted.

\section{REFERENCES}

1 Griffith DE. Overview of nontuberculosis mycobacterial infections in HIV-negative patients. Literature review current through Jun 2017, 2017. www.uptodate.com (accessed 02 Nov 2016).

2 Yoon HJ, Choi HY, Ki M. Nontuberculosis mycobacterial infections at a specialized tuberculosis treatment centre in the Republic of Korea. BMC Infect Dis 2017;17:432.

3 Lee $B$, Reichman MD, Alfred A, et al. Adherence to tuberculosis treatment. Literature review current through 2017, 2017. www.uptodate.com (accessed 19 Jun 2016).

Copyright 2018 BMJ Publishing Group. All rights reserved. For permission to reuse any of this content visit

http://group.bmj.com/group/rights-licensing/permissions.

BMJ Case Report Fellows may re-use this article for personal use and teaching without any further permission.

Become a Fellow of BMJ Case Reports today and you can:

- Submit as many cases as you like

- Enjoy fast sympathetic peer review and rapid publication of accepted articles

- Access all the published articles

Re-use any of the published material for personal use and teaching without further permission

For information on Institutional Fellowships contact consortiasales@bmjgroup.com

Visit casereports.bmj.com for more articles like this and to become a Fellow 